ARTICLE

\title{
Iron phthalocyanine with coordination induced electronic localization to boost oxygen reduction reaction
}

Kejun Chen ${ }^{1,9}$, Kang Liư ${ }^{1,9}$, Pengda An¹,2, Huangjingwei Li ${ }^{1}$, Yiyang Lin¹, Junhua Hu (D) ${ }^{3}$, Chuankun Jia ${ }^{4}$, Junwei Fu', Hongmei Li ${ }^{1}$, Hui Liu ${ }^{5}$, Zhang Lin (10 ${ }^{5}$, Wenzhang Li ${ }^{6}$, Jiahang Li ${ }^{7}$, Ying-Rui Lu ${ }^{8}$, Ting-Shan Chan ${ }^{8}$, Ning Zhang ${ }^{2} \&$ Min Liu (i) ${ }^{1 凶}$

Iron phthalocyanine $(\mathrm{FePc})$ is a promising non-precious catalyst for the oxygen reduction reaction (ORR). Unfortunately, FePc with plane-symmetric $\mathrm{FeN}_{4}$ site usually exhibits an unsatisfactory ORR activity due to its poor $\mathrm{O}_{2}$ adsorption and activation. Here, we report an axial $\mathrm{Fe}-\mathrm{O}$ coordination induced electronic localization strategy to improve its $\mathrm{O}_{2}$ adsorption, activation and thus the ORR performance. Theoretical calculations indicate that the $\mathrm{Fe}-\mathrm{O}$ coordination evokes the electronic localization among the axial direction of O-FeN $\mathrm{N}_{4}$ sites to enhance $\mathrm{O}_{2}$ adsorption and activation. To realize this speculation, FePc is coordinated with an oxidized carbon. Synchrotron X-ray absorption and Mössbauer spectra validate Fe-O coordination between FePc and carbon. The obtained catalyst exhibits fast kinetics for $\mathrm{O}_{2}$ adsorption and activation with an ultralow Tafel slope of $27.5 \mathrm{mV} \mathrm{dec}^{-1}$ and a remarkable half-wave potential of $0.90 \mathrm{~V}$. This work offers a new strategy to regulate catalytic sites for better performance.

\footnotetext{
${ }^{1}$ State Key Laboratory of Powder Metallurgy, School of Physical and Electronics, Central South University, Changsha 410083, China. ${ }^{2}$ School of Materials Science and Engineering, Central South University, Changsha 410083, China. ${ }^{3}$ School of Materials Science and Engineering, Zhengzhou University, Zhengzhou 450002, China. ${ }^{4}$ College of Materials Science and Engineering, Changsha University of Science \& Technology, Changsha 410114, China. ${ }^{5}$ School of Metallurgy and Environment, Central South University, Changsha 410083, China. ${ }^{6}$ School of Chemistry and Chemical Engineering, Central South University, Changsha 410083, China. ${ }^{7}$ Changjun High School of Changsha, Changsha 410002, China. ${ }^{8}$ National Synchrotron Radiation Research Center, 300 Hsinchu, Taiwan. ${ }^{9}$ These authors contributed equally: Kejun Chen, Kang Liu. ${ }^{凶}$ email: minliu@csu.edu.cn
} 
S ince the oxygen reduction reaction (ORR) directly determines the energy efficiency of fuel cells and metal-air batteries, catalytic activation of oxygen $\left(\mathrm{O}_{2}\right)$ to accelerate the kinetics of ORR is crucial for these devices ${ }^{1-6}$. Though platinum (Pt)-based catalysts exhibit excellent $\mathrm{O}_{2}$ adsorption and activation abilities in ORR, the high price and low reserve sternly restrict their large-scale applications ${ }^{7-10}$. Exploring non-Pt ORR catalysts with high efficiency is imperative for further development of fuel cells and metal-air batteries ${ }^{11-13}$. Among the reported non-Pt ORR catalysts, iron phthalocyanine $(\mathrm{FePc})$ molecular catalyst has aroused much attentions due to its special $\mathrm{FeN}_{4}$ active site and low reaction energy barrier during ORR processes ${ }^{14-16}$. However, $\mathrm{FePc}$ possesses a typical two dimensional and plane symmetric structure, which leads to the symmetric electron distribution in the well-defined $\mathrm{FeN}_{4}$-active sites and is not conducive to the $\mathrm{O}_{2}$ adsorption and activation ${ }^{17,18}$. Therefore, breaking the symmetry of electronic density would be an effective strategy to enhance the $\mathrm{O}_{2}$ adsorption/activation and then greatly improve the ORR activity of the FePc catalyst.

From the molecular structure, $\mathrm{FePc}$ with a tetracoordinate planar $\mathrm{FeN}_{4}$ center offers extra coordination sites in the axial direction ${ }^{19,20}$, suggesting the symmetric electronic density can be modulated by suitable axial coordination ${ }^{20-23}$. Generally, the organic ligands with rich electron-donating functional groups, including oxygenic, nitrogenous, and sulfurous species, can be easily employed to coordinate with $\mathrm{FePc}^{24-26}$. However, organic ligands are not favored for electrocatalysis due to their poor conductivity. Modifying the surface of conductive carbon materials with oxygenic groups for stronger electron donation to $\mathrm{FePc}$ provides an alternative way to overcome the problem of conductivity, and realize axial coordination of $\mathrm{O}-\mathrm{FeN}_{4}$ sites ${ }^{17,26,27}$. The axial coordination of $\mathrm{O}-\mathrm{FeN}_{4}$ can break the electronic distribution symmetry of Fe, leading to better oxygen adsorption and activation abilities, and superior ORR activity than those of the FePc catalyst with symmetric $\mathrm{FeN}_{4}$ sites.

In this work, we design a composite catalyst (FeAB-O) by coordination of the $\mathrm{FePc}$ molecule with oxygen-containing groups on an $\mathrm{O}_{2}$ plasma-treated acetylene black (AB-O) matrix to achieve efficient $\mathrm{O}_{2}$ adsorption and ORR. Theoretical calculations show that the axial $\mathrm{O}$ coordination $\left(\mathrm{O}-\mathrm{FeN}_{4}\right)$ sites greatly break the electronic distribution symmetry of $\mathrm{Fe}$ and lead to electron localization on $\mathrm{O}$. The obvious electronic localization on $\mathrm{O}-\mathrm{FeN}_{4}$ sites is beneficial for the axial $\mathrm{O}_{2}$ adsorption and activation. X-ray adsorption experiments and the $\mathrm{O}_{2}$ adsorption/ desorption tests confirm the axial $\mathrm{O}$ coordination and outstanding $\mathrm{O}_{2}$ adsorption capacity of the FeAB-O catalyst, respectively. The ORR performance measurements show that the optimized FeAB-O catalyst has an ultralow Tafel slope of $27.5 \mathrm{mV} \mathrm{dec}^{-1}$ and a superior half-wave potential of $0.90 \mathrm{~V}$ vs. reversible hydrogen electrode (RHE), which is 30 and $50 \mathrm{mV}$ higher than FePc supported onto acetylene black (AB) without axial $\mathrm{O}$ coordination $(\mathrm{FePc} / \mathrm{AB})$ and $\mathrm{Pt} / \mathrm{C}$, respectively. This work opens a new avenue to improve the ORR performance of metal phthalocyanine catalysts, and inspires electronic localization of active sites for regulating catalytic reaction activity.

\section{Results}

Theoretical calculations. Axial $\mathrm{O}$ coordination in $\mathrm{FeAB}-\mathrm{O}$ and no $\mathrm{O}$ coordination in $\mathrm{FePc} / \mathrm{AB}$ were clearly showed in the schematic diagrams (Fig. 1a), which leads to obvious differences on the electron localization functions (Fig. 1b). As expected, the $\mathrm{FePc} / \mathrm{AB}$ shows a symmetric charge distribution. Instead, strong electronic localization on the axial $\mathrm{O}$ atom accompanying with axial asymmetrical electronic distribution of $\mathrm{O}-\mathrm{FeN}_{4}$ sites can be observed in $\mathrm{FeAB}-\mathrm{O}$. By analyzing the charge density differences and spin density (Supplementary Figs. 1 and 2), we found that the charges number and spin polarization of the symmetrical $\mathrm{FeN}_{4}$ site did not significantly change, due to their weaker interaction. However, the axial $\mathrm{O}$ coordination accepts partial charges from the $\mathrm{FeN}_{4}$ site to form the electron localization in $\mathrm{FeAB}-\mathrm{O}^{28-30}$, which break the symmetry of electronic density near the $\mathrm{FeN}_{4}$ site and change the spin polarization of $\mathrm{FeN}_{4}$ site, obviously.

To study the interaction between catalysts and the adsorbed $\mathrm{O}_{2}$, the $\mathrm{O}_{2}$ adsorption energy, charge density differences (between catalysts and adsorbed $\mathrm{O}_{2}$ ), Bader charge analysis, projected density of states (PDOS), and spin density were performed (Fig. 1c, Supplementary Figs. 3 and 4$)^{31}$. As predicted, the FeAB-O shows much higher $\mathrm{O}_{2}$ adsorption energy of $0.92 \mathrm{eV}$ than that of $\mathrm{FePc} / \mathrm{AB}$ with $0.72 \mathrm{eV}$. Correspondingly, the charge transfers from $\mathrm{FeAB}-\mathrm{O}$ and $\mathrm{FePc} / \mathrm{AB}$ to the adsorbed $\mathrm{O}_{2}$ (Fig. 1c) are 0.38 and $0.28 e$, respectively. In addition, the PDOS and spin density of $\mathrm{O}_{2}{ }^{*}$ adsorption on the $\mathrm{FeAB}-\mathrm{O}$ show that the $3 d$ electrons of $\mathrm{Fe}$ and the $2 p$ electrons of $\mathrm{O}$ form stronger hybrid states below the Fermi level, and the spin polarization of oxygen molecule was broken (Supplementary Figs. 3 and 4). These results reveal that electronic localization on axial $\mathrm{O}$ coordination $\left(\mathrm{O}-\mathrm{FeN} \mathrm{N}_{4}\right.$ sites) enhances $\mathrm{O}_{2}$ adsorption and activation.

To study the effect of electronic localization on the ORR processes, the free energies of ORR pathways on $\mathrm{FeAB}-\mathrm{O}$ and $\mathrm{FePc} / \mathrm{AB}$ were calculated (Fig. 1d). The free energy diagrams also show that the intermediate species adsorbed on FeAB-O is more stable than that on $\mathrm{Fe} / \mathrm{AB}$. Both the rate-determining steps on $\mathrm{FeAB}-\mathrm{O}$ and $\mathrm{FePc} / \mathrm{AB}$ are the oxygen adsorption/activation steps:

$$
\mathrm{O}_{2}{ }^{*}+\mathrm{H}^{+}+e^{-} \rightarrow \mathrm{OOH}^{*}
$$

Thus, the stable adsorption of reactant (oxygen) can facilitate the process of ORR. The corresponding overpotential of ORR on $\mathrm{FeAB}-\mathrm{O}$ and $\mathrm{FePc} / \mathrm{AB}$ are 0.70 and $0.80 \mathrm{~V}$, respectively, suggesting the superior ORR performance of $\mathrm{FeAB}-\mathrm{O}$ than that of $\mathrm{FePc} / \mathrm{AB}$. Therefore, the axial $\mathrm{Fe}-\mathrm{O}$ coordination-induced electronic localization to improve the $\mathrm{O}_{2}$ adsorption and activation can boost the ORR performance.

Catalyst synthesis and characterization. Inspired by the theoretical prediction, the $\mathrm{FeAB}-\mathrm{O}$ catalyst was prepared by compositing of $\mathrm{FePc}$ with the $\mathrm{AB}-\mathrm{O}$ in dimethyformamide (DMF) solution. The control sample without $\mathrm{O}$ coordination $(\mathrm{FePc} / \mathrm{AB})$ was obtained by direct physical mixture of FePc and AB. X-ray diffraction (XRD) patterns and Fourier transform infrared (FTIR) spectra reveal that both $\mathrm{Fe} A B-\mathrm{O}$ and $\mathrm{FePc} / \mathrm{AB}$ are comprised

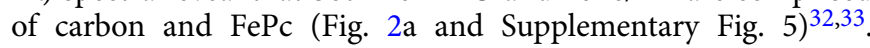
Scanning electron microscope (SEM) and transmission electron microscope (TEM) images (Supplementary Figs. 6a-d and 7a) show uniform carbon nanoparticles, and there is no agglomerate FePc (Supplementary Fig. 6e) to be detected on the carbon matrix in FeAB-O. The elemental mapping from Supplementary Fig. 7b-f display overlapped distribution of $\mathrm{C}, \mathrm{N}, \mathrm{O}$, and $\mathrm{Fe}$, verifying the uniform distribution of $\mathrm{FePc}$ in $\mathrm{FeAB}-\mathrm{O}$.

In order to investigate the presence of axial $\mathrm{O}$ coordination, high-resolution X-ray photon spectroscopy (XPS) spectra and synchrotron X-ray absorption spectra were conducted (Fig. 2b-d). The fitted ratio of $\mathrm{Fe}-\mathrm{O}$ to $\mathrm{Fe}-\mathrm{N}$ bonds in $\mathrm{FeAB}-\mathrm{O}$ shows obvious increase compared with that in $\mathrm{FePc} / \mathrm{AB}^{34}$, indicating more axial $\mathrm{O}$ coordination with $\mathrm{FeN}_{4}$ sites in $\mathrm{FeAB}-\mathrm{O}$. X-ray absorption nearedge spectra (XANES) of Fe K-edge (Fig. 2c) show obvious positive shift in $\mathrm{FeAB}-\mathrm{O}$ compared with in $\mathrm{FePc} / \mathrm{AB}$, indicating the change of electronic structure of $\mathrm{Fe}^{35}$. Moreover, a pre-edge peak around $7114 \mathrm{eV}$ can be indexed to the square-planar and centrosymmetric $\mathrm{Fe}-\mathrm{N}_{4}$ structure of $\mathrm{FePc}^{36-38}$. It should be mentioned that $\mathrm{FeAB}-\mathrm{O}$ exhibits a lower peak intensity of in-plane $\mathrm{FeN}_{4}$ structure than that 
a
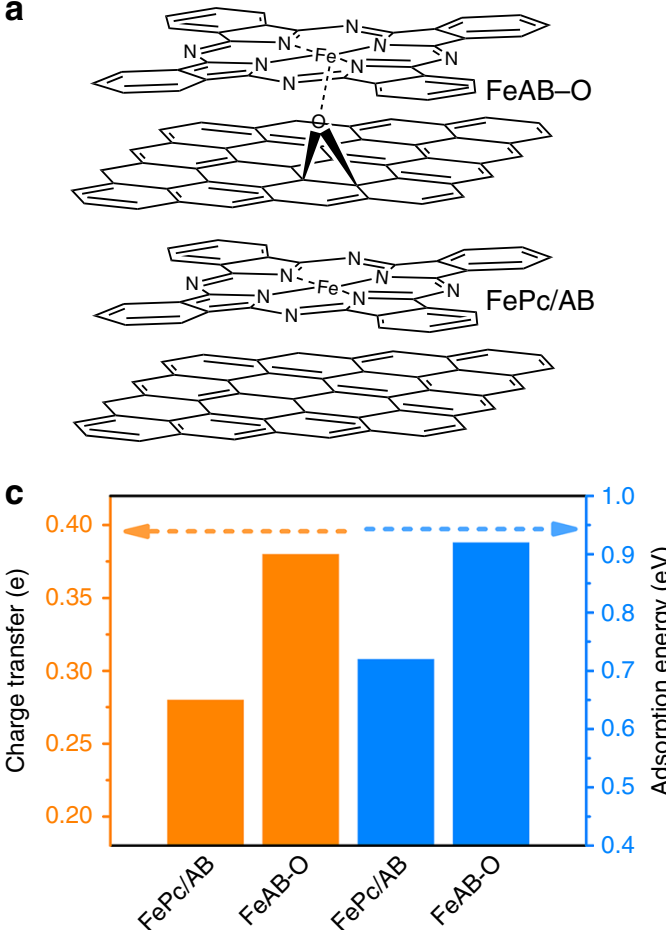
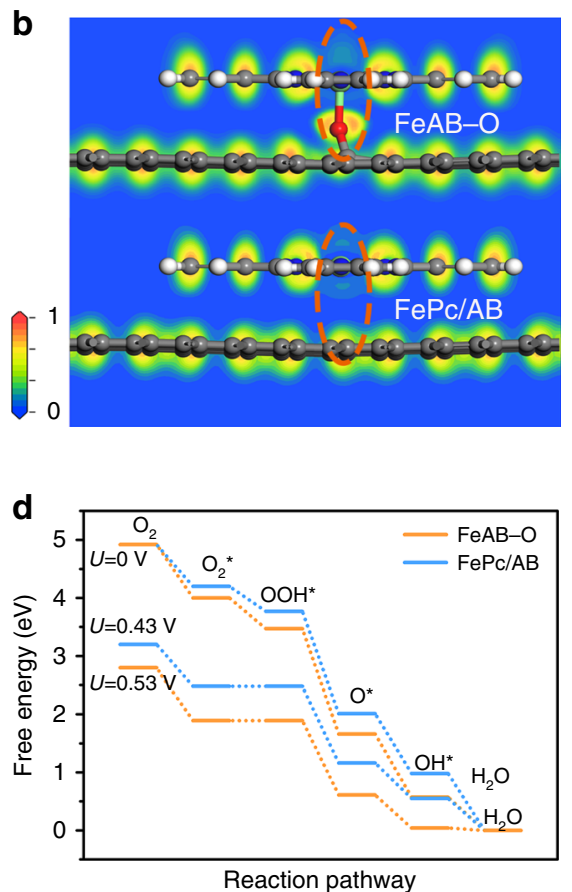

Fig. 1 Theoretical calculations. a Molecular structure models. $\mathbf{b}$ Electron localization functions and $\mathbf{c}$ Bader charge transfers and the $\mathrm{O}_{2}$ adsorption energies of $\mathrm{FeAB}-\mathrm{O}$ and $\mathrm{FePc} / \mathrm{AB}$. d Free energy diagrams of ORR pathways on $\mathrm{FeAB}-\mathrm{O}$ and $\mathrm{FePc} / \mathrm{AB}$.
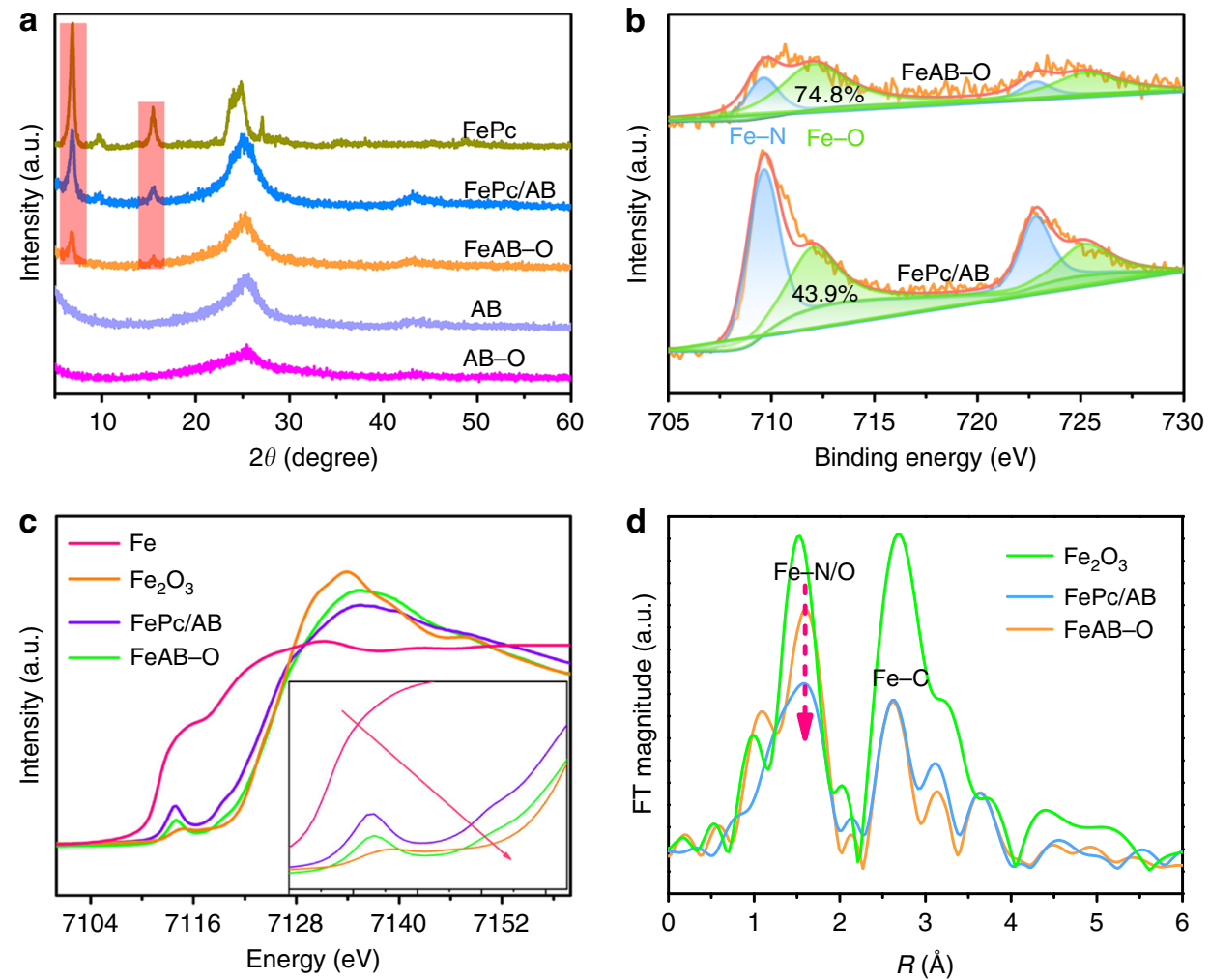

Fig. 2 Structure characterization. a XRD patterns of the pristine $F e A B-O, F e P c / A B, A B, A B-O$, and FePc. $\mathbf{b} X P S$ Fe $2 p$ spectra of the FeAB-O and FePc/AB. c XANES spectra at Fe K-edge of the FeAB-O, FePc/AB, Fe, and $\mathrm{Fe}_{2} \mathrm{O}_{3}$. d Extended X-ray absorption fine structure (EXAFS) spectra of Fe K-edge in the $\mathrm{FeAB}-\mathrm{O}, \mathrm{FePc} / \mathrm{AB}$, and $\mathrm{Fe}_{2} \mathrm{O}_{3}$. 
a

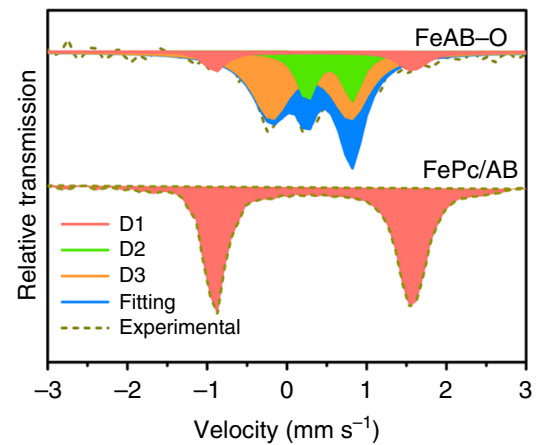

C

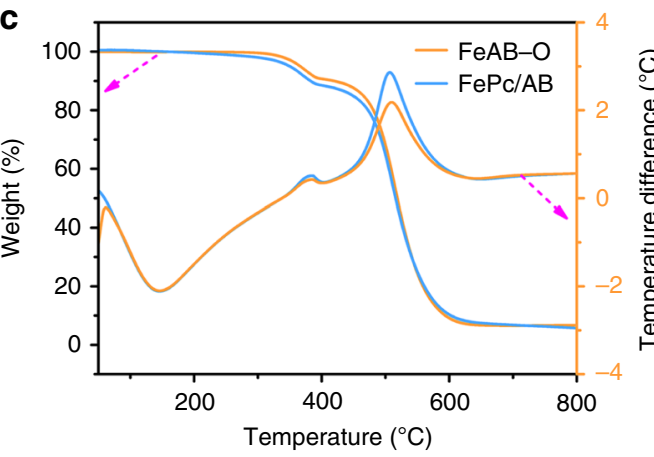

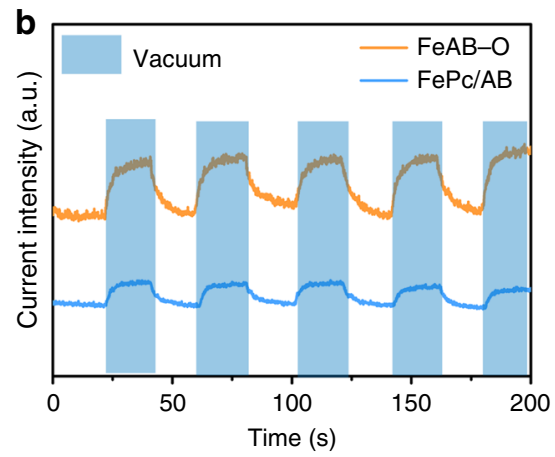

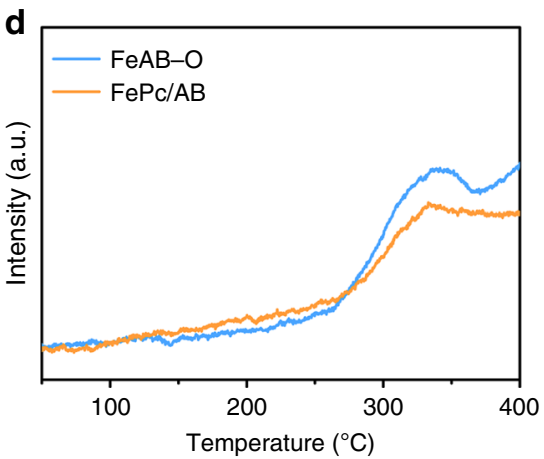

Fig. 3 The Oxygen adsorption ability. a ${ }^{57} \mathrm{Fe}$ Mössbauer transmission spectrum. b The oxygen adsorption-desorption tests. c TGA curves in air atmosphere. d The $\mathrm{O}_{2}-\mathrm{TPD}$ curves of FeAB-O and FePc/AB.

of $\mathrm{FePc} / \mathrm{AB}$, which can be attributed to the axial coordination breaking the in-plane $\mathrm{Fe}-\mathrm{N}_{4}$ structure ${ }^{17,39}$. Additionally, extended $\mathrm{X}$-ray absorption fine structure (EXAFS) spectra of Fe K-edge show that the coordination number of $\mathrm{Fe}$ in $\mathrm{FeAB}-\mathrm{O}$ is higher than the precise four nitrogen-coordination $\left(\mathrm{FeN}_{4}\right)$ and lower than the six-oxygen coordination $\left(\mathrm{FeO}_{6}\right)$ in $\mathrm{Fe}_{2} \mathrm{O}_{3}$, respectively ${ }^{40,41}$. These characterization results prove the formation of axial $\mathrm{O}$ coordination between the $\mathrm{FePc}$ and oxygen group of $\mathrm{AB}-\mathrm{O}$ in FeAB-O.

To obtain more structure information, the ${ }^{57} \mathrm{Fe}$ Mössbauer spectra were collected at $300 \mathrm{~K}$. As shown in Fig. 3a, the Mössbauer spectrum of $\mathrm{FePc} / \mathrm{AB}$ has a doublet peaks (D1), which can be assigned to the square planar $\mathrm{FeN}_{4}$ species $^{20}$. As for FeAB-O, there is a small D1 doublet peaks and two obvious D2 and D3 doublet peaks. The D2 peaks are from the $\mathrm{O}-\mathrm{FeN}_{4}$ species, and the $\mathrm{D} 3$ peaks can be attributed to the $\mathrm{O}-\mathrm{FeN}_{4}$ sites with surface-adsorbed $\mathrm{O}_{2}$ molecule $\left(\mathrm{O}-\mathrm{FeN}_{4}-\mathrm{O}_{2}\right)^{39}$. No clear $\mathrm{O}_{2}$ adsorption signal can be observed in $\mathrm{FePc} / \mathrm{AB}$. These results confirmed the axial $\mathrm{O}$ coordination of $\mathrm{O}-\mathrm{FeN}_{4}$ and the enhanced $\mathrm{O}_{2}$ adsorption.

To prove the enhanced $\mathrm{O}_{2}$ adsorption, the $\mathrm{O}_{2}$ adsorption-desorption performances were measured (Fig. $3 \mathrm{~b}-\mathrm{d}$ and Supplementary Fig. 8). Obviously, FeAB-O exhibits stronger $\mathrm{O}_{2}$ adsorption response than $\mathrm{FePc} / \mathrm{AB}$, suggesting better $\mathrm{O}_{2}$ adsorption ability of FeAB-O than that of FePc/AB ${ }^{42}$. The $\mathrm{O}_{2}$ temperature-programmed desorption (TPD) measurements were also performed to investigate the $\mathrm{O}_{2}$ adsorption property. According to the thermogravimetry analysis (TGA) of FeAB-O and $\mathrm{FePc} / \mathrm{AB}$ (Fig. $3 \mathrm{c}$ ), the weight loss at 380 and $507^{\circ} \mathrm{C}$ can be ascribed to the decomposition of FePc and carbon, respectively. In Fig. 3d, the $\mathrm{O}_{2}$-desorption peaks located at $340{ }^{\circ} \mathrm{C}$ can be assigned to the release of chemistry-adsorbed $\mathrm{O}_{2}$ in the samples ${ }^{43}$. Interestingly, the $\mathrm{O}_{2}$-desorption peak of $\mathrm{FeAB}-\mathrm{O}$ is higher than that of $\mathrm{FePc} / \mathrm{AB}$, indicating the robust $\mathrm{O}_{2}$ adsorption ability of $\mathrm{FeAB}-\mathrm{O}$.
Evaluating catalyst performance for ORR. To identify the electrochemical ORR properties of catalysts, the cyclic voltammetry $(\mathrm{CV})$ was measured in $0.1 \mathrm{M} \mathrm{KOH}$. As presented in Fig. $4 \mathrm{a}$, the $\mathrm{CV}$ curve of FeAB-O in $\mathrm{N}_{2}$-saturated electrolyte contains two pairs of peaks located at 0.8 and $0.3 \mathrm{~V}$. The former is indexed to the reduction/oxidation peaks of $\mathrm{Fe}^{3+} / \mathrm{Fe}^{2+}$, the latter is signed to redox couple of $\mathrm{Fe}^{2+} / \mathrm{Fe}^{+38}$. With the increasing of dissolved $\mathrm{O}_{2}$ molecule, obvious new reduction peaks located at about $0.9 \mathrm{~V}$ occur and increase, even beyond the reduction peak of $\mathrm{Fe}^{3+} / \mathrm{Fe}^{2+}$, suggesting the active site of variable $\mathrm{O}-\mathrm{FeN}_{4}$. However, the $\mathrm{FePc} /$ $\mathrm{AB}$ and the pristine $\mathrm{FePc}$ display was negligible in these two groups of peaks in Supplementary Fig. 9a, suggesting that the oxygenic carbon coordination with $\mathrm{FePc}$ via $\mathrm{Fe}-\mathrm{O}$ is beneficial for electronic delocalization of $\mathrm{Fe}$ to form the active site. The $\mathrm{CV}$ curves of the control samples under $\mathrm{N}_{2}$ and $\mathrm{O}_{2}$-saturated electrolyte were also conducted and shown in Supplementary Fig. 9b-d. All the samples exhibit obvious oxygen reduction peaks and $\mathrm{FeAB}-\mathrm{O}$ displays the most positive potential, indicating the optimal ORR performance of FeAB-O.

Next, the linear scan voltammetry (LSV) curves of FeAB-O and $\mathrm{FePc} / \mathrm{AB}$ were conducted to further study their ORR properties (Fig. 4b). The theoretical calculations, electrochemical impedance spectroscopy (EIS), and resistance tests (Supplementary Fig. 10 and Supplementary Note 1) demonstrate that the electrons can transfer from the electrode to FePc molecule through the $\mathrm{Fe}-\mathrm{O}$ bonds with the help of electric field. Thus, FeAB-O presents a remarkable $E_{1 / 2}$ of $0.90 \mathrm{~V}$ and a calculated kinetic current density $\left(J_{\mathrm{k}}\right)$ of $24.0 \mathrm{~mA} \mathrm{~cm}^{-2}$ at $0.88 \mathrm{~V}$, which are much superior to FePc/AB $\left(E_{1 / 2}=0.87 \mathrm{~V}, J_{\mathrm{k}}=1.9 \mathrm{~mA} \mathrm{~cm}^{-2}\right.$ at $0.88 \mathrm{~V})$ and $\mathrm{Pt} / \mathrm{C}\left(E_{1 / 2}=0.85 \mathrm{~V}, J_{\mathrm{k}}=4.0 \mathrm{~mA} \mathrm{~cm}^{-2}\right.$ at $\left.0.88 \mathrm{~V}\right)$. Instead, the $\mathrm{AB}, \mathrm{AB}-\mathrm{O}$, and $\mathrm{FePc}$ only exhibit inferior half-wave potentials $\left(E_{1 / 2}\right)$ and limited current density $\left(J_{\mathrm{L}}\right)$ in Supplementary Fig. 11a. Moreover, FePc is physically mixed with $\mathrm{AB}-\mathrm{O}$ ( $\mathrm{FePc} / \mathrm{AB}-\mathrm{O})$ to exclude the effect of carbon substrate. As expected, the $\mathrm{FePc} / \mathrm{AB}-\mathrm{O}$ displays the alike performance of $\mathrm{FePc} /$ 

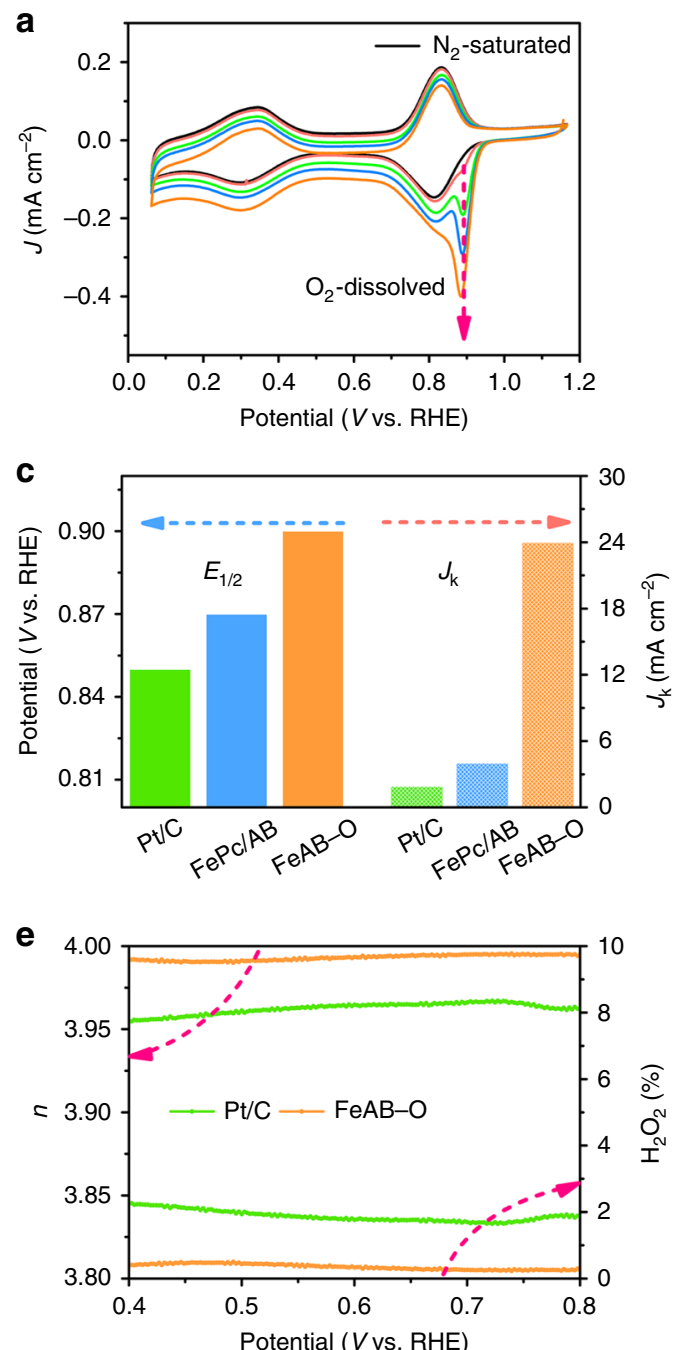
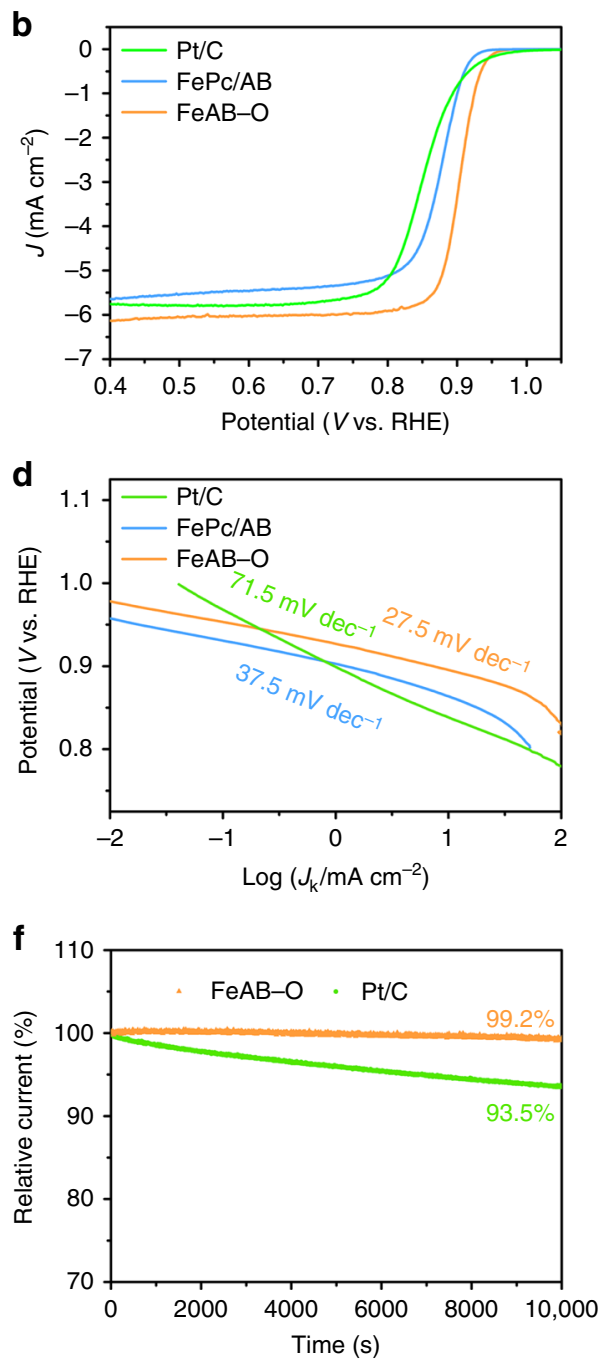

Fig. 4 Electrochemical ORR performances. a Cyclic voltammetry profiles of $\mathrm{FeAB}-\mathrm{O}$ in $\mathrm{N}_{2}$-saturated and $\mathrm{O}_{2}$-dissolved $0.1 \mathrm{M} \mathrm{KOH}$ solution. b ORR polarization curves of $\mathrm{FeAB}-\mathrm{O}, \mathrm{FePc} / \mathrm{AB}$, and $\mathrm{Pt} / \mathrm{C}$ in $\mathrm{O}_{2}$-saturated $0.1 \mathrm{M} \mathrm{KOH}$. c Values of half-wave potentials and $\mathrm{J}_{\mathrm{k}}$ at $0.88 \mathrm{~V}$ of $\mathrm{FeAB}-\mathrm{O}, \mathrm{FePc} / \mathrm{AB}$, and $\mathrm{Pt} / \mathrm{C}$. d Corresponding Tafel plots of $\mathrm{FeAB}-\mathrm{O}, \mathrm{FePc} / \mathrm{AB}$, and Pt/C. e Electron transfer numbers and proportion of produced $\mathrm{H}_{2} \mathrm{O}_{2}$ in $\mathrm{FeAB}-\mathrm{O}$ and $\mathrm{Pt} / \mathrm{C}$. $\mathbf{f} \mathrm{I}-\mathrm{t}$ chronoamperometry responses (in $\mathrm{O}_{2}$-saturated $0.1 \mathrm{M} \mathrm{KOH}$ with a rotation of $1600 \mathrm{rpm}$ ) of $\mathrm{FeAB}-\mathrm{O}$ and $\mathrm{Pt} / \mathrm{C}$.

$\mathrm{AB}$ in Supplementary Fig. 11b. Based on these results, the introduction of axial $\mathrm{O}$ coordination in $\mathrm{O}-\mathrm{FeN}_{4}$ sites can greatly boost the performance of ORR. The ORR catalytic activity of $\mathrm{FeAB}-\mathrm{O}$ is superior to most of reported $\mathrm{Fe}-\mathrm{N}-\mathrm{C}$ catalysts in recent literatures (Supplementary Table 1). Notably, the FeAB-O has the most excellent Tafel slope of $27.5 \mathrm{mV} \mathrm{dec}^{-1}$, which is lower than those of $\mathrm{FePc} / \mathrm{AB}\left(37.5 \mathrm{mV} \mathrm{dec}{ }^{-1}\right)$ and $\mathrm{Pt} / \mathrm{C}(71 \mathrm{mV}$ $\mathrm{dec}^{-1}$ ), confirming the fastest kinetic process of FeAB-O for $\mathrm{O}_{2}$ adsorption/activation and ORR.

The selectivity of ORR in FeAB-O was studied by rotating ring disk electrode (RRDE) measurements. Compared with $\mathrm{Pt} / \mathrm{C}$, the higher electron transfer number and lower $\mathrm{H}_{2} \mathrm{O}_{2}$ yield can be observed in FeAB-O (Fig. 4e), indicating the ORR on FeAB-O is a typical four-electron reduction process, and the main product is $\mathrm{H}_{2} \mathrm{O}$.

To explore the practical application of FeAB-O, long-term catalytic stability and methanol tolerance tests were performed at reduced potential of $0.4 \mathrm{~V}$ vs. RHE. As for the traditional $\mathrm{Pt} / \mathrm{C}$ catalyst, $\mathrm{Pt}$ nanoparticles tend to aggregate after long-term ORR measurements, which leads to a decrease in activity and durability ${ }^{44}$. In this work, the ORR current density of FeAB-O maintained a level of $99.2 \%$ for over $10,000 \mathrm{~s}$ chronoamperometric I-t tests, exceeding that of $\mathrm{Pt} / \mathrm{C}(93.5 \%)$ and $\mathrm{FePc} / \mathrm{AB}$ (88.3\%) (Fig. $4 \mathrm{f}$ and Supplementary Fig. 12a). The outstanding durability of FeAB-O for ORR can be attributed to the high dispersity and stability of the $\mathrm{O}-\mathrm{FeN}_{4}$ sites $^{17,45}$. No current oscillation was observed in FeAB-O when methanol is added (Supplementary Fig. 12b), while a clear decline of current appears in Pt/C. A home-made aluminum-air battery was used to evaluate the practical performance of $\mathrm{FeAB}-\mathrm{O}$. The battery with FeAB-O as cathode catalyst shows higher open potential than that with $\mathrm{Pt} / \mathrm{C}$ as cathode catalyst (Supplementary Fig. 12c). The corresponding discharge plots of long-term discharge were performed at current density of $50 \mathrm{~mA} \mathrm{~cm}^{-2}$. As shown in Supplementary Fig. 12d, the FeAB-O exhibits superior performance than that of the commercialized $\mathrm{Pt} / \mathrm{C}$. These results demonstrated that $\mathrm{FeAB}-\mathrm{O}$ has excellent potential for practical application.

To further confirm the importance of the axial $\mathrm{O}$ coordination of $\mathrm{O}-\mathrm{FeN}_{4}, \mathrm{FeAB}$ with less axial $\mathrm{O}$ coordination was prepared by compositing of $\mathrm{FePc}$ with $\mathrm{AB}$ treated by $\mathrm{O}_{2}$-plasma for only 10 min in DMF solution. XRD and FT-IR characterization results (Supplementary Fig. 13a, b) prove the presence of FePc and carbon in FeAB. The Fe2p XPS spectrum (Supplementary Fig. 13c) indicates the presence of axial $\mathrm{O}$ coordination in FeAB. The EXAFS results (Supplementary Fig. 13d) show the order of 
Fe coordination number is $\mathrm{FeAB}-\mathrm{O}>\mathrm{FeAB}>\mathrm{FePc} / \mathrm{AB}$. These structural characterizations confirm the axial $\mathrm{O}$ coordination in $\mathrm{FeAB}$ is between $\mathrm{FeAB}-\mathrm{O}$ and $\mathrm{FePc} / \mathrm{AB}$. As we expected, the electrochemical ORR performance of FeAB (Supplementary Fig. $14 \mathrm{a}, \mathrm{b}$ ) is also between $\mathrm{FeAB}-\mathrm{O}$ and $\mathrm{FePc} / \mathrm{AB}$, confirming the axial $\mathrm{O}$ coordination induced the electronic localization, which improves the $\mathrm{O}_{2}$ adsorption and then boosts ORR activity of catalysts.

\section{Discussion}

In summary, we proposed a coordination-induced electronic localization strategy to tune the $\mathrm{O}_{2}$ adsorption ability and ORR performance of $\mathrm{FeN}_{4}$ sites in FePc. DFT calculations demonstrated that the axial $\mathrm{O}$ coordination of $\mathrm{O}-\mathrm{FeN}_{4}$ sites breaks the symmetrical electronic density and promotes the electronic localization of Fe sites. XPS, XAS, Mössbauer spectra, and $\mathrm{O}_{2}$ adsorption/desorption processes indicated the enhanced ORR catalytic activity is ascribed to the strengthened $\mathrm{O}_{2}$ adsorption and accelerated charge transfer from $\mathrm{Fe}$ to $\mathrm{O}_{2}$ molecule. As a result, the $\mathrm{FeAB}-\mathrm{O}$ with optimal axial $\mathrm{O}$ coordination exhibited a record Tafel slope of $27.5 \mathrm{mV} \mathrm{dec}^{-1}$ and one of the best half-wave potential of $0.90 \mathrm{~V}$ vs. RHE, which was much superior to commercial $\mathrm{Pt} / \mathrm{C}$. The axial $\mathrm{O}$ coordination number is positively correlated to ORR performance. This work provides a new strategy to regulate the electronic localization property of catalytic active sites for affecting the adsorption of the reactants and accelerating catalytic reactions.

\section{Methods}

Chemicals and materials. FePc, dimethylformamide (DMF), potassium chloride $(\mathrm{KCl})$, indium hydroxide $\left(\mathrm{In}(\mathrm{OH})_{3}\right)$, zinc oxide $(\mathrm{ZnO})$, sodium stannate $\left(\mathrm{Na}_{2} \mathrm{SnO}_{3}\right)$, and potassium hydroxide $(\mathrm{KOH})$ were bought from Shanghai Aladdin reagent co. Ltd. Pt/C (20 wt\%) and the raw AB were purchased from Alfa Aesar and Shenzhen Kejing co. Ltd, respectively. All of the chemical reagents were used as received without any other purification.

Synthesis of catalysts. The surface of the $\mathrm{AB}$ was decorated with oxygencontaining groups by $\mathrm{O}_{2}$-plasma treatment. Typically, the raw $\mathrm{AB}$ was treated in the $\mathrm{O}_{2}$ plasma for $30 \mathrm{~min}$ with $100 \mathrm{~W}$ generator power (denoted as $\mathrm{AB}-\mathrm{O}$ ). Then, the as obtained $\mathrm{AB}-\mathrm{O}(25 \mathrm{mg})$ was added into $60 \mathrm{~mL}$ of DMF solution encompassed $5 \mathrm{mg}$ of $\mathrm{FePc}$. To get the uniform suspension, the mixture solution was subjected to ultrasonical treatment for $1 \mathrm{~h}$ and then stirred overnight at room temperature. Finally, the FeAB-O composite was collected by filtration of the resulting solution and washing with ethanol. The obtained sample was dried in vacuum at $60^{\circ} \mathrm{C}$ for $12 \mathrm{~h}$. The $\mathrm{FeAB}$ with less axial $\mathrm{O}$ coordination was obtained by the same steps just by replacing the $\mathrm{AB}-\mathrm{O}$ matrix with $\mathrm{AB}$ treated by $\mathrm{O}_{2}$-plasma for $10 \mathrm{~min}$ at $100 \mathrm{~W}$. The $\mathrm{FePc} / \mathrm{AB}$ and $\mathrm{FePc} / \mathrm{AB}-\mathrm{O}$ were obtained by direct physical mixture of $\mathrm{FePc}$ with the $\mathrm{AB}$ and $\mathrm{AB}-\mathrm{O}$, respectively.

Characterizations. XRD data was collected by using a RIGAKU Rint-2000 X-ray diffractometer (graphite monochromatized $\mathrm{Cu}$-Ka radiation with $\lambda=1.54184 \AA$ ). X-ray photoelectron spectroscopy (XPS) was measured by Thermo ESCALAB 250XI. FTIR measurements were performed by the Thermo iS50. The thermogravimetric experiments were conducted on TG 209 F3 Tarsus under the air atmosphere from the room temperature to $900{ }^{\circ} \mathrm{C}$ with heating rate of $10^{\circ} \mathrm{C} \mathrm{min}^{-1}$. Scanning electron microscopy (SEM) was measured by a Quanta 200 field-emission SEM system. The transmission electron microscopy (TEM) images were achieved on Tecnai G2 F20. The ${ }^{57}$ Fe Mössbauer spectra were achieved by using an MS-500 instrument (Germany, Wissel) in transmission geometry with constant acceleration mode at room temperature. The $\mathrm{O}_{2}$-TPD of the samples was measured using AutoChem II 2920 apparatus. The catalyst $(100 \mathrm{mg})$ was pretreated at $150^{\circ} \mathrm{C}$ and purged with helium (He) for $2 \mathrm{~h}$, and then cooled down to room temperature. And then, the catalyst was purged with $5 \% \mathrm{O}_{2} / \mathrm{He}$ at $25^{\circ} \mathrm{C}$ for $2 \mathrm{~h}$. Finally, the desorption profile of $\mathrm{O}_{2}$ was recorded online under the atmosphere of $\mathrm{He}$.

Electrochemical measurements. All of the electrochemical experiments were implemented with an electrochemical station of Auto Lab in a typical threeelectrode system. The $\mathrm{Ag} / \mathrm{AgCl}$ (saturated $\mathrm{KCl}$ ) electrode, carbon rod, and glassy carbon electrode (GCE) were used as the reference electrode, counter electrode, and working electrode, respectively. In this work, all electrode potentials were referenced to the reversible hydrogen elecrtrode (RHE) based on the following calculation equations:

$$
E_{\mathrm{RHE}}=E_{\mathrm{AgCl}}^{0}+E_{\mathrm{AgCl}}+0.059 \times \mathrm{pH}
$$

where $E_{\mathrm{AgCl}}^{0}($ saturated $\mathrm{KCl})=0.197 \mathrm{~V}\left(25^{\circ} \mathrm{C}\right)$.

The catalyst ink was prepared by ultrasonic dispersion of $4 \mathrm{mg}$ of catalyst in a hybrid solution included $60 \mu \mathrm{L}$ of Nafion ( $5 \mathrm{wt} \%), 470 \mu \mathrm{L}$ of alcohol, and $470 \mu \mathrm{L}$ of $\mathrm{H}_{2} \mathrm{O}$. All of the catalysts were cast onto the RDE $\left(0.19625 \mathrm{~cm}^{-2}\right)$ and RRDE $\left(0.2475 \mathrm{~cm}^{-2}\right)$ with a loading amount of $0.2 \mathrm{mg} \mathrm{cm}^{-2}$, and contrast sample of $\mathrm{Pt} / \mathrm{C}$ was dropped RRDE with a loading amount of $0.1 \mathrm{mg} \mathrm{cm}^{-2}$. Cyclic voltammograms (CV) measurements were performed with scan rate of $50 \mathrm{mV} \mathrm{s}^{-1}$ in the $\mathrm{N}_{2}$ or $\mathrm{O}_{2}$ satureated $0.1 \mathrm{M} \mathrm{KOH}$ solution. The catalytic activity of samples was evaluated by using linear sweep voltammetry (LSV) at scan rate of $10 \mathrm{mV} \mathrm{s}^{-1}$ with different rotation rates. The electron transfer number $(n)$ of catalysts was calculated through the Koutecky-Levich (K-L) equations:

$$
\begin{gathered}
\frac{1}{J}=\frac{1}{J_{\mathrm{L}}}+\frac{1}{J_{\mathrm{k}}}=\frac{1}{B \omega^{1 / 2}}+\frac{1}{J_{\mathrm{k}}} \\
B=0.62 n F D_{\mathrm{o}}^{2 / 3} \nu^{-1 / 6} C_{\mathrm{o}}
\end{gathered}
$$

where $J, J_{\mathrm{L}}$, and $J_{\mathrm{k}}$ represents the measured, diffusion-limiting, and the kinetic current density, individually. $\omega$ is the electrode-rotating angular velocity, $F$ is the Faraday constant $\left(96,485 \mathrm{C} \mathrm{mol}^{-1}\right), D_{\mathrm{o}}$ is the diffusion coefficient of $\mathrm{O}_{2}$ $\left(1.9 \times 10^{-5} \mathrm{~cm}^{2} \mathrm{~s}^{-1}\right.$ in $\left.0.1 \mathrm{M} \mathrm{KOH}\right), v$ is kinetic viscosity $\left(0.01 \mathrm{~cm}^{2} \mathrm{~s}^{-1}\right)$ of the electrolyte, and $C_{\mathrm{o}}$ is the density of $\mathrm{O}_{2}\left(1.2 \times 10^{-6} \mathrm{~mol} \mathrm{~cm}^{-3}\right)$.

Tafel slope was achieved from the Tafel equation:

$$
E=a+b \log \left(J_{k}\right)
$$

where $E$ is the applied potential of LSV tests, $a$ is a constant, $b$ is the Tafel slope and $J_{\mathrm{k}}$ is the kinetic current density. Moreover, the yields of peroxide species and the electron transfer number can be calculated from the LSV of RRDE measurement at $1600 \mathrm{rpm}$ via as following equation:

$$
\begin{gathered}
n=4 \frac{I_{\mathrm{D}}}{I_{\mathrm{D}}+I_{\mathrm{R}} / N} \\
\mathrm{H}_{2} \mathrm{O}_{2}(\%)=200 \frac{I_{\mathrm{R}} / N}{I_{\mathrm{D}}+\left(I_{\mathrm{R}} / N\right)}
\end{gathered}
$$

where $I_{\mathrm{D}}$ and $I_{\mathrm{R}}$ is the disk current and ring current, respectively. The $N$ represents the current collection efficiency equaled to 0.37 of the RRDE in our experimental system.

Assembly of Al-air batteries. In a typical $\mathrm{Al}$-air batteries, the polished aluminum plate is used as anode. The electrolyte is $6 \mathrm{M} \mathrm{KOH}$ contained $0.0005 \mathrm{M} \operatorname{In}(\mathrm{OH})_{3}$ $0.0075 \mathrm{M} \mathrm{ZnO}$, and $0.01 \mathrm{M} \mathrm{Na}_{2} \mathrm{SnO}_{3}$; the gas diffusion electrode with catalystloading amount of $2.0 \mathrm{mg} \mathrm{cm}^{-2}$ is employed as cathode in a home-made cell model. As a control, the commercial $\mathrm{Pt} / \mathrm{C}(20 \mathrm{wt} \%)$ was also assembled in similar mode. The measurement of batteries was performed on the LAND testing system.

Computation methods. Our simulation study was calculated by using the Vienna ab initio simulation package (VASP) ${ }^{46}$. The PAW potentials describe the interaction of electron-ion ${ }^{47}$. The generalized gradient approximation of Perdew-Burke-Ernzerhof (PBE) was employed to describe the electron-electron exchange and correlation functional ${ }^{48}$. A plane wave cutoff energy of $400 \mathrm{eV}$ was applied in our calculations. A rectangular supercell containing 180 carbon atoms are used as substrate. Spin-polarized calculations were employed for all systems. van der Waals (VDW) forces were corrected with the D2 method of Grimme ${ }^{49}$. The Gamma-point-only grid was used during the optimization. The convergence criterion was set $0.02 \mathrm{eV}^{-1}$ for the force and $10^{-5} \mathrm{eV}$ per atom for energy. We used the correlation energy $(U)$ of $4 \mathrm{eV}$ and the exchange energy $(J)$ of $1 \mathrm{eV}$ for Fe $3 d$ orbitals $^{50}$.

The Gibbs free energy can be expressed as

$$
\Delta G=\Delta E+\Delta \mathrm{ZPE}-T \cdot \Delta S
$$

where $\Delta E$ is the reaction energy calculated by the DFT methods, $\Delta \mathrm{ZPE}$ the changes in zero-point energies, and $\Delta S$ the entropy during the reaction, respectively.

\section{Data availability}

The data that support the findings of this study are available from the corresponding author on reasonable request.

Received: 14 January 2020; Accepted: 29 July 2020; Published online: 20 August 2020 


\section{References}

1. Guo, D. et al. Active sites of nitrogen-doped carbon materials for oxygen reduction reaction clarified using model catalysts. Science 351, 361 (2016).

2. Pegis, M. L., Wise, C. F., Martin, D. J. \& Mayer, J. M. Oxygen reduction by homogeneous molecular catalysts and electrocatalysts. Chem. Rev. 118, 2340-2391 (2018).

3. Li, W., Yu, A., Higgins, D. C., Llanos, B. G. \& Chen, Z. Biologically inspired highly durable iron phthalocyanine catalysts for oxygen reduction reaction in polymer electrolyte membrane fuel cells. J. Am. Chem. Soc. 132, 17056-17058 (2010).

4. Wang, Q. et al. Bioinspired fiber-like porous $\mathrm{Cu} / \mathrm{N} / \mathrm{C}$ electrocatalyst facilitating electron transportation toward oxygen reaction for metal-air batteries. Nanoscale 10, 15819-15825 (2018).

5. He, T. et al. Architecture of $\mathrm{CoN}_{\mathrm{x}}$ single clusters on nanocarbon as excellent oxygen reduction catalysts with high-efficient atomic utilization. Nanoscale 9 , 8341-8348 (2017).

6. Wu, N. et al. Facile synthesis of FeCo@NC core-shell nanospheres supported on graphene as an efficient bifunctional oxygen electrocatalyst. Nano Res. 10, 2332-2343 (2017).

7. Li, J. et al. Atomically dispersed manganese catalysts for oxygen reduction in proton-exchange membrane fuel cells. Nat. Catal. 1, 935-945 (2018).

8. Rowley-Neale, S. J. et al. $2 \mathrm{D}$ molybdenum disulphide $\left(2 \mathrm{D}-\mathrm{MoS}_{2}\right)$ modified electrodes explored towards the oxygen reduction reaction. Nanoscale $\mathbf{8}$, 14767-14777 (2016).

9. Cheng, Y. et al. Iron single atoms on graphene as nonprecious metal catalysts for high-temperature polymer electrolyte membrane fuel cells. Adv. Sci. 6, 1802066 (2019).

10. Zhou, B. et al. Platinum nanostructures via self-assembly of an amyloid-like peptide: a novel electrocatalyst for the oxygen reduction. Nanoscale $\mathbf{5}$, 2669-2673 (2013).

11. Chen, Y. et al. Enhanced oxygen reduction with single-atomic-site iron catalysts for a zinc-air battery and hydrogen-air fuel cell. Nat. Commun. 9, 5422 (2018)

12. Zhao, L. et al. Cascade anchoring strategy for general mass production of high-loading single-atomic metal-nitrogen catalysts. Nat. Commun. 10, 1278 (2019).

13. Liu, J. et al. Confining ultrasmall bimetallic alloys in porous $\mathrm{N}$-carbon for use as scalable and sustainable electrocatalysts for rechargeable $\mathrm{Zn}$-air batteries. J. Mater. Chem. A 7, 12451-12456 (2019).

14. Zhang, Z., Dou, M., Ji, J. \& Wang, F. Phthalocyanine tethered iron phthalocyanine on graphitized carbon black as superior electrocatalyst for oxygen reduction reaction. Nano Energy 34, 338-343 (2017).

15. Wang, Y., Yuan, H., Li, Y. \& Chen, Z. Two-dimensional iron-phthalocyanine $(\mathrm{Fe}-\mathrm{Pc})$ monolayer as a promising single-atom-catalyst for oxygen reduction reaction: a computational study. Nanoscale 7, 11633-11641 (2015).

16. Fu, J., Jiang, K., Qiu, X., Yu, J. \& Liu, M. Product selectivity of photocatalytic $\mathrm{CO}_{2}$ reduction reactions. Mater. Today 32, 222-243 (2020).

17. Cao, R. et al. Promotion of oxygen reduction by a bio-inspired tethered iron phthalocyanine carbon nanotube-based catalyst. Nat. Commun. 4, 2076 (2013).

18. Han, Y. et al. Electronic structure engineering to boost oxygen reduction activity by controlling the coordination of the central metal. Energy Environ. Sci. 11, 2348-2352 (2018).

19. Peng, Y. et al. Probing the influence of the center atom coordination structure in iron phthalocyanine multi-walled carbon nanotube-based oxygen reduction reaction catalysts by X-ray absorption fine structure spectroscopy. J. Power Sources 291, 20-28 (2015).

20. $\mathrm{Li}, \mathrm{Z}$. et al. The marriage of the $\mathrm{FeN}_{4}$ moiety and MXene boosts oxygen reduction catalysis: Fe $3 d$ electron delocalization matters. Adv. Mater. 30, 1803220 (2018).

21. Jiang, Y. et al. Enhanced catalytic performance of Pt-free iron phthalocyanine by graphene support for efficient oxygen reduction reaction. ACS Catal. 3, 1263-1271 (2013).

22. Li, J. et al. Structural and mechanistic basis for the high activity of Fe-N-C catalysts toward oxygen reduction. Energy Environ. Sci. 9, 2418-2432 (2016).

23. Sedona, F. et al. Tuning the catalytic activity of $\operatorname{Ag}(110)$-supported Fe phthalocyanine in the oxygen reduction reaction. Nat. Mater. 11, 970-977 (2012).

24. Nemykin, V. N., Purchel, A. A., Spaeth, A. D. \& Barybin, M. V. Probing the electronic properties of a trinuclear molecular wire involving isocyanoferrocene and iron(II) phthalocyanine motifs. Inorg. Chem. 52, 11004-11012 (2013).

25. Janczak, J. \& Kubiak, R. Pyrazine control of the supramolecular chemistry of iron(ii) and cobalt(ii) phthalocyanines. CrystEngComm 12, 3599-3606 (2010).

26. Han, Z., Han, X., Zhao, X., Yu, J. \& Xu, H. Iron phthalocyanine supported on amidoximated PAN fiber as effective catalyst for controllable hydrogen peroxide activation in oxidizing organic dyes. J. Hazard. Mater. 320, 27-35 (2016).
27. Martin, B. \& Autschbach, J. Kohn-Sham calculations of NMR shifts for paramagnetic $3 d$ metal complexes: protocols, delocalization error, and the curious amide proton shifts of a high-spin iron(ii) macrocycle complex. Phys. Chem. Chem. Phys. 18, 21051-21068 (2016).

28. Mukherjee, M., Samanta, M., Banerjee, P., Chattopadhyay, K. K. \& Das, G. P. Endorsement of manganese phthalocyanine microstructures as electrocatalyst in ORR: experimental and computational study. Electrochim. Acta 296, 528-534 (2019).

29. Wei, Y. et al. New strategy for designing orangish-redemitting phosphor via oxygen-vacancy-induced electronic localization. Light-Sci. Appl. 8, 15 (2019).

30. Zhou, Y. et al. Dopant-induced electron localization drives $\mathrm{CO}_{2}$ reduction to $\mathrm{C}_{2}$ hydrocarbons. Nat. Chem. 10, 974-980 (2018).

31. Liu, K. et al. Single-atom transition metals supported on black phosphorene for electrochemical nitrogen reduction. Nanoscale 12, 4903-4908 (2020).

32. Chen, K. et al. Untying thioether bond structures enabled by "voltage-scissors" for stable room temperature sodium-sulfur batteries. Nanoscale 11, 5967-5973 (2019)

33. Chen, K., Hou, H., Huang, C., Ji, X. \& Qiu, X. Constructing hierarchical sulfur-doped nitrogenous carbon nanosheets for sodium-ion storage. Nanotechnology 28, 445604 (2017).

34. Yan, X. et al. The effect of oxygen content of carbon nanotubes on the catalytic activity of carbon-based iron phthalocyanine for oxygen reduction reaction. Electrochim. Acta 281, 562-570 (2018).

35. Xue, Z. et al. Missing-linker metal-organic frameworks for oxygen evolution reaction. Nat. Commun. 10, 5048 (2019).

36. Ramaswamy, N., Tylus, U., Jia, Q. \& Mukerjee, S. Activity descriptor identification for oxygen reduction on nonprecious electrocatalysts: linking surface science to coordination chemistry. J. Am. Chem. Soc. 135, 15443-15449 (2013).

37. Jia, Q. et al. Experimental observation of redox-induced Fe-N switching behavior as a determinant role for oxygen reduction activity. ACS Nano $\mathbf{9}$ 12496-12505 (2015).

38. Alsudairi, A. et al. Resolving the iron phthalocyanine redox transitions for ORR catalysis in aqueous media. J. Phys. Chem. Lett. 8, 2881-2886 (2017)

39. Cheng, W. et al. Boosting defective carbon by anchoring well-defined atomically dispersed metal- $\mathrm{N}_{4}$ sites for ORR, OER, and $\mathrm{Zn}$-air batteries. Appl. Catal. B Environ. 260, 118198 (2020).

40. $\mathrm{Fu}$, J. et al. Graphitic carbon nitride with dopant induced charge localization for enhanced photoreduction of $\mathrm{CO}_{2}$ to $\mathrm{CH}_{4}$. Adv. Sci. 6, 1900796 (2019).

41. Fu, J. et al. Graphitic carbon nitride based single-atom photocatalysts. Front Phys. 15, 33201 (2020).

42. Cao, S. et al. Ultrasmall $\mathrm{CoP}$ nanoparticles as efficient cocatalysts for photocatalytic formic acid dehydrogenation. Joule 2, 549-557 (2018).

43. Liu, Z., Li, J. \& Wang, R. $\mathrm{CeO}_{2}$ nanorods supported M-Co bimetallic oxides $(\mathrm{M}=\mathrm{Fe}, \mathrm{Ni}, \mathrm{Cu})$ for catalytic $\mathrm{CO}$ and $\mathrm{C}_{3} \mathrm{H}_{8}$ oxidation. J. Colloid Int. Sci. 560, 91-102 (2020).

44. Nie, Y. et al. Pt/C trapped in activated graphitic carbon layers as a highly durable electrocatalyst for the oxygen reduction reaction. Chem. Commun. $\mathbf{5 0}$, 15431-15434 (2014)

45. Guo, J. et al. The synthesis and synergistic catalysis of iron phthalocyanine and its graphene-based axial complex for enhanced oxygen reduction. Nano Energy 46, 347-355 (2018).

46. Kresse, G. \& Hafner, J. Ab initio molecular-dynamics simulation of the liquidmetal-amorphous-semiconductor transition in germanium. Phys. Rev. B 49, 14251 (1994)

47. Blöchl, P. E. Projector augmented-wave method. Phys. Rev. B 50, 17953 (1994).

48. Perdew, J. P., Burke, K. \& Ernzerhof, M. Generalized gradient approximation made simple. Phys. Rev. Lett. 77, 3865 (1996).

49. Grimme, S. Semiempirical GGA-type density functional constructed with a long-range dispersion correction. J. Comput. Chem. 27, 1787-1799 (2006).

50. Zhou, J. \& Sun, Q. Magnetism of phthalocyanine-based organometallic single porous sheet. J. Am. Chem. Soc. 133, 15113-15119 (2011).

\section{Acknowledgements}

The authors gratefully thank the International Science and Technology Cooperation Program (Grant Nos. 2017YFE0127800 and 2018YFE0203400), Natural Science Foundation of China (Grant Nos. 21872174 and U1932148), Hunan Provincial Science and Technology Program (No. 2017XK2026), Project of Innovation-Driven Plan in Central South University (2017CX003, 20180018050001), Shenzhen Science and Technology Innovation Project (Grant No. JCYJ20180307151313532), Ministry of Science and Technology, Taiwan (Contract No. MOST108-2113-M-213-006), China Postdoc Innovation Talent Support Program, China Postdoctoral Science Foundation (Grant No. 2018M640759), Thousand Youth Talents Plan of China, and Hundred Youth Talents Program of Hunan. 


\section{Author contributions}

M.L., N.Z., and H.M.L. conceived the project; K.C. and M.L. designed the experiments and analyzed the results. K.C., P.A., H.J.W.L., Y.Y.L., and J.L. synthesized the samples, performed the electrochemical experiments, and analyzed the results. K.L. and H.L. carried out the simulations and wrote the corresponding section. K.L., Y.Y.L., Y.-R.L. and T.-S.C. conducted the XAS measurements. J.F., C.J., Z.L., J.H., and W.L. carried out the electron microscope measurements. All authors read and commented on the manuscript.

\section{Competing interests}

The authors declare no competing interests.

\section{Additional information}

Supplementary information is available for this paper at https://doi.org/10.1038/s41467020-18062-y.

Correspondence and requests for materials should be addressed to M.L.

Peer review information Nature Communications thanks the anonymous reviewers for their contribution to the peer review of this work.
Reprints and permission information is available at http://www.nature.com/reprints

Publisher's note Springer Nature remains neutral with regard to jurisdictional claims in published maps and institutional affiliations.

\section{(c) (i)}

Open Access This article is licensed under a Creative Commons Attribution 4.0 International License, which permits use, sharing, adaptation, distribution and reproduction in any medium or format, as long as you give appropriate credit to the original author(s) and the source, provide a link to the Creative Commons license, and indicate if changes were made. The images or other third party material in this article are included in the article's Creative Commons license, unless indicated otherwise in a credit line to the material. If material is not included in the article's Creative Commons license and your intended use is not permitted by statutory regulation or exceeds the permitted use, you will need to obtain permission directly from the copyright holder. To view a copy of this license, visit http://creativecommons.org/ licenses/by/4.0/.

(C) The Author(s) 2020 